\title{
New Automated and High-Throughput Quantitative Analysis of Urinary Ketones by Multifiber Exchange-Solid Phase Microextraction Coupled to Fast Gas Chromatography/Negative Chemical-Electron Ionization/Mass Spectrometry
}

\author{
Marco Pacenti, ${ }^{1}$ Stefano Dugheri, ${ }^{1}$ Pietro Traldi, ${ }^{2}$ Filippo Degli Esposti, ${ }^{3}$ Nicola Perchiazzi, ${ }^{3}$ \\ Elena Franchi, ${ }^{4}$ Massimo Calamante, ${ }^{4}$ Ireneo Kikic, ${ }^{5}$ Paolo Alessi, ${ }^{5}$ Alice Bonacchi, ${ }^{1}$ \\ Edoardo Salvadori, ${ }^{1}$ Giulio Arcangeli, ${ }^{1}$ and Vincenzo Cupelli ${ }^{1}$ \\ ${ }^{1}$ Occupational Health Division, Department of Public Health, Viale Morgagni 48, University of Florence, 50100 Florence, Italy \\ ${ }^{2}$ CNR-Istitute of Molecular Science and Technologies, Corso Stati Uniti 4, 35100 Padova, Italy \\ ${ }^{3}$ Chromline Srl, Via Anita Garibaldi 40, 59100 Prato, Italy \\ ${ }^{4}$ Organic Chemistry Department/ProtEra Srl (Spin Off of Magnetic Resonance Center), Via Lastruccia 13, University of Florence, \\ Sesto Fiorentino, 50019 Florence, Italy \\ ${ }^{5}$ Department of Chemical, Environmental and Raw Materials Engineering (DICAMP), Piazzale Europa 1, University of Trieste, \\ 34127 Trieste, Italy
}

Correspondence should be addressed to Stefano Dugheri, dugheris@aou-careggi.toscana.it

Received 16 December 2009; Accepted 12 April 2010

Academic Editor: Peter B. Stockwell

Copyright (C) 2010 Marco Pacenti et al. This is an open access article distributed under the Creative Commons Attribution License, which permits unrestricted use, distribution, and reproduction in any medium, provided the original work is properly cited.

The present research is focused on automation, miniaturization, and system interaction with high throughput for multiple and specific Direct Immersion-Solid Phase Microextraction/Fast Gas Chromatography analysis of the urinary ketones. The specific Mass Spectrometry instrumentation, capable of supporting such the automated changeover from Negative Chemical to Electron Ionization mode, as well as the automation of the preparation procedure by new device called MultiFiber Exchange, through change of the fibers, allowed a friendly use of mass spectrometry apparatus with a number of advantages including reduced analyst time and greater reproducibility (2.01-5.32\%). The detection limits for the seven ketones were less than $0.004 \mathrm{mg} / \mathrm{L}$. For an innovative powerful meaning in high-throughput routine, the generality of the structurally informative Mass Spectrometry fragmentation patterns together with the chromatographic separation and software automation are also investigated.

\section{Introduction}

Methyl ethyl ketone (MEK), methyl isobuthyl ketone (MIBK), cyclohexanone (CHone), 2,5 hexanedione (2,5 $\mathrm{HD}$ ), and acetone (Ace) are ketones monitored in urine to obtain an indication of occupational exposure or environmental contamination to MEK, MIBK, cyclohexane, hexane, methyl butyl ketone, and Ace [1]. These solvents are widely used in mixtures rather than as an unmixed single solvent, and various Authors have indicated that metabolic interactions exist in acute or chronic coexposure [2]. All these urinary Biological Exposure Indices (BEIs) are widely considered by the American Conference of Governmental Industrial Hygienists (ACGIH) that indicated for them health-based values. They have been used as indicators of human exposure to these solvents even though it is not clear if these substances are the most suitable for this purpose, because of a large variability in the threshold concentrations of these five ketones excreted by nonoccupationally exposed individuals. So the specificity of unmetabolized Ace as a marker for workplace Ace exposure may be limited since this molecule may derive from ketone bodies that include also 3hydroxybutyrate $(\mathrm{BOHB})$ and acetoacetate $(\mathrm{AcAc})$, present in the urine of all humans, but in elevated concentrations 
when associated with diabetic-, alcoholic-, and starvationketoacidoses [3]. Also the validity of the use of total 2,5 $\mathrm{HD}$ (obtained from the acid hydrolysis of urine at $\mathrm{pH} 0.1$, which corresponds to the free $2,5 \mathrm{HD}$ plus 4,5-dihydroxy2-hexanedione and 5-hydroxy-2-hexanone converted into $2,5 \mathrm{HD}$ during hydrolysis) as opposed to free 2,5 $\mathrm{HD}$, for biological monitoring, has been the basis of a considerable controversy [4]. For many years, ACGIH recommended the determination of total $2,5 \mathrm{HD}$, with $\mathrm{BEI}$ of $5.0 \mathrm{mg} / \mathrm{L}$. In 2003 ACGIH began to provide additional information on the status of this chemical substance and BEI of $0.4 \mathrm{mg} / \mathrm{L}$ for free 2,5 HD was published.

For these reasons simultaneous and more sensitive assay methods than those available were needed and the necessity for standardization of analytical factors affecting these ketones determination has been indicated in a number of researches [5-7]. Apart from biomonitoring applications, these ketones show different concentrations in urine and thus, either gas chromatography (GC), GC-mass spectrometry (MS), liquid chromatography (LC)-tandem MS, selected ion flow tube-MS, or dipstick methods were developed for measuring single or multiple compounds for similar urinary concentration levels [8-14]. However, no single automated procedure is currently capable of quantization the following urinary ketones: MEK, MIBK, CHone, free 2,5 HD, Ace, $\mathrm{BOHB}$, and AcAc. Furthermore, in these previous works, the use of solvents and/or clean-up steps were often necessary to extract and eliminate interfering compounds from the urine. This implies an increase of the required manual operations, bigger costs, uncertainty in the analysis determination, and the possible loss of the analyte. Accordingly, we sought to simplify the situation by developing new ketones preparation methods where the ability of direct immersion (DI) solid phase microextraction (SPME) techniques by on-sample and on-fiber derivatization has been demonstrated also theoretically, together with the quantitative determination by Fast GC/Negative Chemical Ionization (NCI)-Electron Ionization (EI)/MS in order to propose a new robotic friendly use MS apparatus able to analyze great quantities of samples.

The Fast GC techniques are based on the use of short capillary column, called narrow bore, that allows the achievement of high-speed separations while maintaining excellent resolution [15]. In the last decade this technique has found routine application by the achievement of adequate specific conditions, as the increased inlet pressures, rapid oven heating rates, and fast electronics for detection and data collection. However, high split ratio is necessary when liquids are injected, because of low sample narrow-bore capillary column capacities that may have an affect on the efficiency. This problem can be easily overcome by the use of SPME, a solvent-free technique that incorporates sampling, isolation, and enrichment into one step. Within analytical chemistry, the SPME analysis of biological samples is an important technology, it is considered one of major ideas that shaped 20th-century analytical chemistry [16], capable of producing powerful diagnostic and identifying important toxicology and disease biomarkers. As interest in this area grows, and the number of such applications continues to increase, the need for efficient, comprehensive, reproducible methods has developed within both experts and nonexperts.

In this work we design an automated multiple assay which meets this need through the development of a new robotic system called MultiFiber Exchange (MFX) installed on a XYZ GC autosampler. As, this increased versatility of MFX allows on-sample and on-fiber SPME derivatization approaches in fully automated mode, the Authors are interested in both O-(2,3,4,5,6, pentafluorobenzyl)hydroxylamine (PFBHA)-oxime derivatives of carbonyl group, where selectivity and sensitivity of the analytical method may be greatly improved by use of NCI, and towards methyl ester and tert-Butyldimethylsilyl (TBDMS) derivatives of carboxylic functional groups, where the reactions occur under mild conditions. The object of this work is obtained assays in automated very short time windows, with consequently more sensitivity power and high discrimination, by structurally informative MS fragmentation pattern, than other techniques for routine employed in toxicological and clinical chemistry laboratories.

\section{Experimental}

2.1. Reagents. O-(2,3,4,5,6, Pentafluorobenzyl)-hydroxylamine (98\%), 2,4-dinitrophenylhydrazine (98\%), pentafluorophenylhydrazine $(98 \%)$, trimethyloxonium tetrafluoroborate, $N$-tert.-butyldimethylsilyl- $N$-methyltrifluoroacetamide (BSTFA, >98\%), methyl ethyl ketone (>99\%), methyl isobuthyl ketone, cyclohexanone (>99\%), acetone (>99.9\%), 2,5 hexanedione (98\%), sodium DL-3hydroxybutyrate, lithium acetoacetate, methanol (>99\%), and internal standard, 2,4 pentanedione (99\%) were purchased from Aldrich (Sigma-Aldrich, Milan, Italy). Ketone-PFBHA-oximes (>99\%), 3-hydroxybutyrate-methylester (>99\%), acetoacetate-PFBHA-oxime-methylester $(>99 \%)$, and internal standard acetoacetate D5 (>99\%) were synthesized from ProtEra (Sesto Fiorentino, Italy). Internal standard sodium DL-3-hydroxybutyrate-2,2-D2 was obtained from $\mathrm{C} / \mathrm{D} / \mathrm{N}$ Isotopes (Chemical Research 2000, Rome, Italy). Urine control for Ace and AcAc (Liquichek Urinalysis Control) was purchased from BioRad Laboratories (Milan, Italy). A multicompound stock solution was prepared in methanol, and by appropriate dilution working standard solutions were obtained. C5-C28 $n$-alkanes (Supelco, Sigma-Aldrich) were used for evaluation of the Linear Temperature-Programmed Retention Index (LTPRI).

2.2. Sample Pretreatments. Two SPME sampling techniques, on-sample derivatization by PFBHA for MEK, MIBK, CHone, free 2,5 HD, Ace, plus trimethyloxonium tetrafluoroborate (TMO) for AcAc and BOHB, and on-fiber derivatization by $N$-tert.-butyldimethylsilyl- $N$ methyltrifluoroacetamide (MTBSTFA) for BOHB and AcAc were investigated.

2.2.1. SPME on-Sample Derivatization by PFBHA and TMO. Two $\mathrm{mL}$ of urine were transferred into a $10 \mathrm{~mL}$ autosampler 


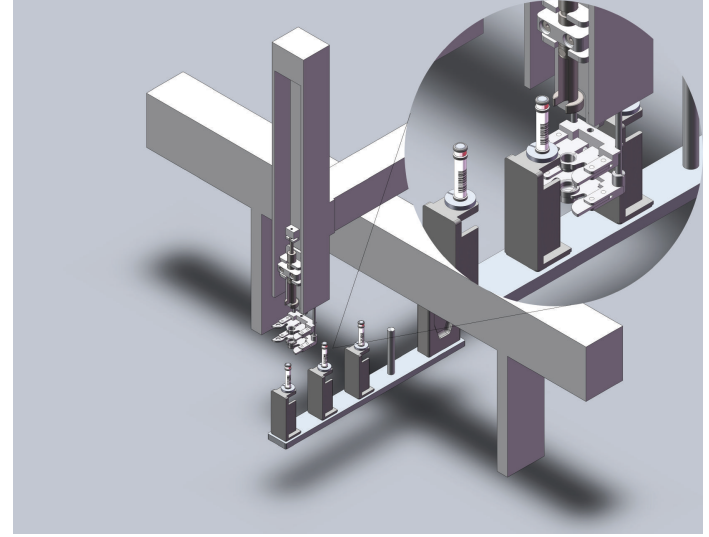

FIGURE 1: XYZ autosampler equipped with 3-position trays MultiFiber Exchange and SPME Fast Fit Assembled.

vial with a magnetic stirring bar and mixed with $10 \mu \mathrm{L} 2,4$ pentanedione solution $240 \mu \mathrm{g} / \mathrm{mL}$ plus $100 \mu \mathrm{L}$ of $40 \mathrm{mg} / \mathrm{mL}$ PFBHA aqueous solution. The condition used for full reaction was 20 hours at room temperature. To convert the AcAcoxime and $\mathrm{BOHB}$ into their methyl esters, derivatization with TMO was performed at room temperature in two steps. While stirring about $20 \mathrm{mg}$ of $\mathrm{Na}_{2} \mathrm{CO}_{3}$ were added and within 4 minutes approximately $30 \mathrm{mg}$ of solid TMO were added in two aliquots. After 1 minute the solution was neutralized with about $15 \mathrm{mg}$ of $\mathrm{NaHCO}_{3}$. This procedure was repeated again. Finally, for head space (HS)-SPME sodium chloride $(0.5 \mathrm{~g})$ was added while for DI-SPME the vial was filled by $8 \mathrm{~mL}$ of water ketones-free and incubated for 2 minutes at $100^{\circ} \mathrm{C}$. The appropriate SPME fiber (see Results and Discussion) was directly immersed for 5 minutes at $50^{\circ} \mathrm{C}$, previous 30 minutes incubation time for HS-SPME, under continuous agitation at $500 \mathrm{rpm}$ and desorbing into GC injector port for 1 minute.

2.2.2. SPME on-Fiber Derivatization by MTBSTFA. SPME extraction was performed by immersing the $85 \mu \mathrm{m}$ polyacrilate (PA) SPME fiber into $2 \mathrm{~mL}$ autosampler vial filled with diluted urine $(1: 5 \mathrm{v} / \mathrm{v})$ in temperature-controlled agitation $\left(50^{\circ} \mathrm{C}\right.$ and $\left.500 \mathrm{rpm}\right)$ for 15 minutes, after addition of $10 \mu \mathrm{L}$ internal standards solution (BOHB d2 and AcAc d5 $25 \mathrm{mg} / \mathrm{mL}$ methanol). On-fiber silylation of BOHB and AcAc were performed by exposing the fiber to the HS in a $2 \mathrm{~mL}$ autosampler vial containing $50 \mu \mathrm{L}$ of MTBSTFA for 15 minutes at $50^{\circ} \mathrm{C}$. PA fiber was desorbed at $270^{\circ} \mathrm{C}$ for 2 minutes.

2.3. Automation of Analytical Procedure. Since the determination of the seven ketones requires different fibers, the object of this paper is focused on the automation of the SPME extraction procedure and on the performance of the Fast GC/MS apparatus. The extraction efficiency for $85 \mu \mathrm{m}$ $\mathrm{PA}$, and 7,30 , and $100 \mu \mathrm{m}$ polydimethylsiloxane (PDMS) fibers was investigated for temperature, agitation, and mass loaded at equilibrium, by SPME MFX.
2.3.1. XYZ Axes Robotic System. New fully automation of the procedure was achieved using a Gerstel MPS2 autosampler equipped with 3-position trays MFX (SRA Instruments, Milan, Italy) and Fast Fit Assemblies (FFAs)-SPME fibers (Supelco, Sigma-Aldrich, Milan, Italy) patented by Chromline (Prato, Italy). FFA is the device that allows to use fibers for fully automated processes. It is formed by adaptors that make the fiber much more robust and identifiable by its barcode. Thanks to FFA it is possible to change SPME fibers in automatic mode by MFX (Figure 1). In this option the fibers are transported between the 3-position tray, the vials, containing urine or derivatization agents, and the injector by new SPME holder equipped with a plunger/magnetic system. At the end of the analysis desorbed fiber is moved back to the tray and the cycle is repeated. Moreover, the autosampler parameters allowed to complete the analysis cycle by conditioning and sealing in the Teflon septum inserted into the tray. The automatically change of SPME fibers and processing using XYZ autosampler is indicated as flowchart in Figure 2.

2.3.2. Fast GC/MS Conditions. The Fast GC-MS conditions were the same for all the sample preparations. The Shimadzu GC 2010 (Shimadzu Italia, Milan, Italy) was equipped with SLB5-MS costumizer column $(5 \mathrm{~m} \times 0.10 \mathrm{~mm}$ internal diameter $\times 0.4 \mu \mathrm{m}$ film thickness, Supelco, Sigma-Aldrich, Milan, Italy); oven setting was $65^{\circ} \mathrm{C}$ hold for 0.3 minutes, with a ramp of $80^{\circ} \mathrm{C} /$ minute up to $100^{\circ} \mathrm{C}$ and $50^{\circ} \mathrm{C} /$ minute up to $275^{\circ} \mathrm{C}$ (total program time 5.24 minutes). Inlet pressure, column flow, and average linear velocity were, respectively, $313.7 \mathrm{Kpa}, 1.00 \mathrm{~mL} / \mathrm{minute}$, and $89.6 \mathrm{~cm} / \mathrm{s}$. The MS detector was a Shimadzu QP 2010 series with the system acquisition GC Solution software 2.5 SU3 version operating in EI for TBDMS-BOHO/AcAc derivatives, methane NCI for PFBHAoxime-/methylester-PFBHA-oximes, and methane positive chemical ionization (PCI) mode for molecular weights identification. Spectra were collected at $0.03 \mathrm{sec}$ event time and detector voltage was set to 800-1300 V. The MS detector was autotimed weekly. MS analysis was operated by the new fast automated scan/selective ion monitoring (SIM) technique (FASST) acquisition mode with scan a range of $\mathrm{m} / \mathrm{z}$ 40-550. For LTPRI the PDMS column was used with the same condition and indicated for Fast GC/EI mode.

2.4. Theory of SPME. Effective use of the theory minimizes the number of experiments that need to be performed and to simplify mathematical relationship the theory assumes idealized condition. Many of these data are now readily available on line and in this way it is possible to know in advance whether or not the DI-SPME method offers some advantages. National Library of Medicine, ChemlDplus, http://toxnet.nlm.nih.gov (accessed November 18, 2009); U.S. Environmental Protection Agency, EPA online tools for site assessment calculation, http://www.epa.gov/ (accessed November 18, 2009); Dortmund Data Bank (DDB), http://www.ddbst.de/new/Default.htm (accessed November 18, 2009); Universal Functional Activity Coefficient (UNIFAC), http://www.unifac.org/ (accessed November 18, 2009), 


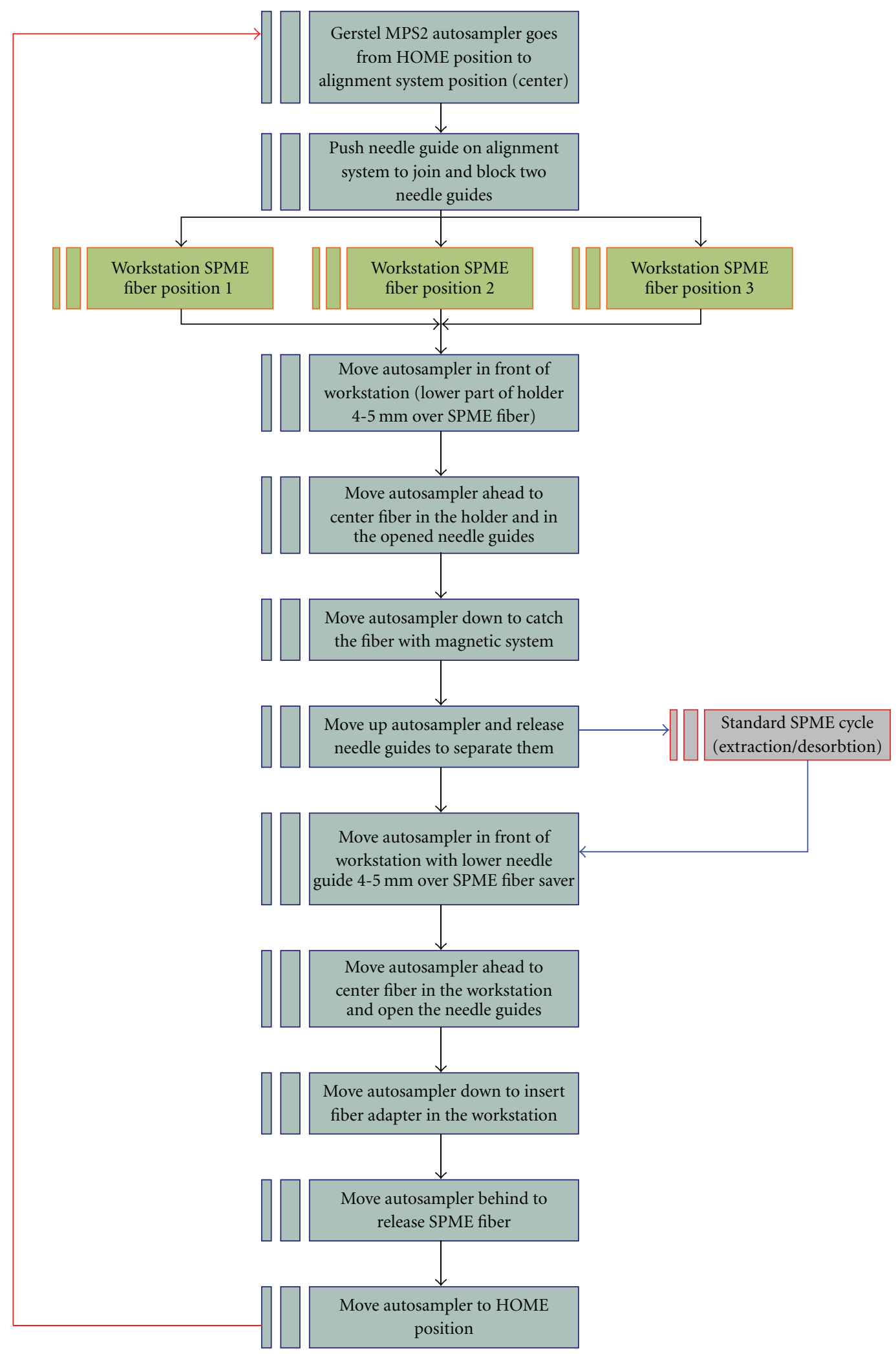

Figure 2: Processing using MFX/XYZ autosampler. 
Physical Properties Database (PHYSPROP) by Syracuse Research Corporation, http://www.srcinc.com (accessed November 18, 2009), as well as publications and texts were looked up in [17-22].

2.5. Calibration Curves, Limits of Detection, within- and between-Rub Precision, and Accuracy. Calibration samples, prepared and analyzed as described above in Section 2, to obtain a calibration curve. A multi-compound stock solution was prepared in methanol, and by appropriate dilution working standard solution was obtained. Six calibrations sample and blank, were obtained; five analysis for each concentration were performed. Least squares linear digression analysis was used to estimate slopes $(m)$ and intercepts $(b)$ of calibration curves $y=m x+b$, where $y$ is the ratio between the chromatographic area of the analyte and the relative internal standard, and $x$ the urinary concentration of the analyte $(\mathrm{mg} / \mathrm{L})$. The Limit of Detection (LOD) of the assay was calculated according to the expression

$$
\mathrm{LOD}=\frac{3 \mathrm{SE}_{b}+b}{m},
$$

where $\mathrm{SE}_{b}$ is the internal standard error of the intercept [23]. The precision of the assay (as a coefficient of variation, C.V.\%) was estimated both a within session and as intersession repeatability by analysis of urine spiked with ketones. Accuracy was evaluated by recoveries (calculated from the ratio percent between the measured and the nominal concentrations in spiked blank urines) at all concentrations used for the calibration plot. Values of the accuracy were compared with the requirement of US Food and Drug Administration for the bioanalytical method validation.

\section{Results and Discussion}

Sampling of urine by DI-SPME sampling and following Fast GC/MS analysis has aroused interest in the authors of this paper and has been investigated as a possible alternative to conventional methods. The aim of this paper is to provide a simple, fast, sensitive, and organic-solvent free innovative procedure for analysis of ketones in urine. So, to achieve successful method, three fundamental requisites were satisfied by the Authors.

3.1. SPME-Development Method. The first objective was to develop the derivatization conditions onto DI-SPME technologies to obtain compounds which are stable under a variety of conditions and easily amenable to sampling, to GC separation, and to MS identification.

\subsubsection{Carbonyl Functional Groups SPME-Derivatization.} Several papers indicate the on-fiber HS SPME to determinate carbonyl functional groups. By this paper, the authors point out the reasons of the rejection of this derivatization technique for the ketones: (i) long periods of equilibrium time for HS; (ii) the range of $K_{H}$ of the involved ketones is too wide, Ace and 2,5 HD $3.8810^{-5}$ and $4.4310^{-8} \mathrm{~atm} \mathrm{~m}^{3} / \mathrm{mol}$ at $25^{\circ} \mathrm{C}$, respectively; and (iii) the excess of PFBHA is an interference on chromatographic separation system.

In-sample derivatization of ketone to hydrazones and oximes is frequently used; the procedure involves derivatization of the analyte with 2,4-dinitrophenylhydrazine [24], 2,4,6-trichlorophenylhydrazine [25], pentafluorophenylhydrazine [26], benzyloxime, or pentafluoro benzyloxime [27]. The analysis of hydrazones is often difficult. For example, the carbonyl of the ketones is hindered, and, thus, the compounds react very slowly with 2,4-dinitrophenylhydrazine. The method potentially allows specific quantitation of ketones by LC but not through GC, since for many hydrazones the maximum product yield was attained at $\mathrm{pH} 1.0$ 1.5. PFBHA reacts in weakly acidic media $(\mathrm{pH} \mathrm{4-6)}$ with carbonyl functional groups to produce the corresponding oxime.

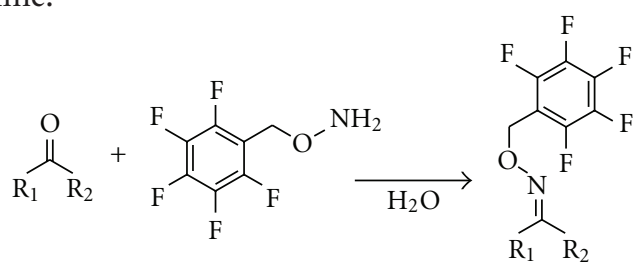

A low recovery of corresponding oxime was observed only for ketones contain chlorine atoms. In fact, the reactivity of chloroketone with PFBHA is triggered by the chlorosubstitution in the principal product [28]. Herein to verify the drawbacks with indicated above methods and in light of previous works $[29,30]$, the authors investigated the derivatization with PFBHA. The reaction was evaluated concerning the effect of the reaction time and product yield attained by the determination of the amount of ketones converting to corresponding oximes. Briefly, $5 \mathrm{~mL}$ of water containing $2 \mu \mathrm{g}$ of MEK, MIBK, Chone, 2,5 HD, and Ace were doped with $1 \mathrm{~mL}$ of PFBHA solution $(40 \mathrm{mg} / \mathrm{mL})$. The samples were left to three experimental derivatization reaction settings $\left(20\right.$ hours at $25^{\circ} \mathrm{C}, 1$ hour at $25^{\circ} \mathrm{C}$, and 30 minutes to $65^{\circ} \mathrm{C}$ ) for establishing the conditions that minimize the time needed for preparation. After incubations, the oximes were extracted twice with $1 \mathrm{~mL}$ of hexane and $0.3 \mu \mathrm{L}$ was analyzed. The GC area counts were compared with the amount of Ace-, MEK-, MIBK-, Chone-, and 2,5 HD-PFBHA-oxime standards previously injected by Fast $\mathrm{GC} / \mathrm{NCI} / \mathrm{MS}$. For 20 hours at $25^{\circ} \mathrm{C}$ incubation ketones were converted in their corresponding derivatives with values of 99\% and no decomposition of PFBHA-oximes was observed (Figure 3). However, the reaction yield after 30 minutes to $65^{\circ} \mathrm{C}$ is enough for the formation of products also ensuring fastness in the application of the method. If higher sensitivity is aimed, the reaction time and exposure fiber can be prolonged based on the profile of the reaction and absorption progress (Figure 4). No decomposition of the excess of derivatization agent by adding $5 \mu \mathrm{L}$ of $9 \mathrm{M}$ sulfuric acid was necessary if overnight incubation was employed. Eventually, the selective reduction of this bond with pyridine:borane reagent leads to single GC peak for each compound [31]. For following sampling by DI, the effect of agitation and the absorption-time profiles on the SPME extraction efficiency of the derivatives of these carbonyl 


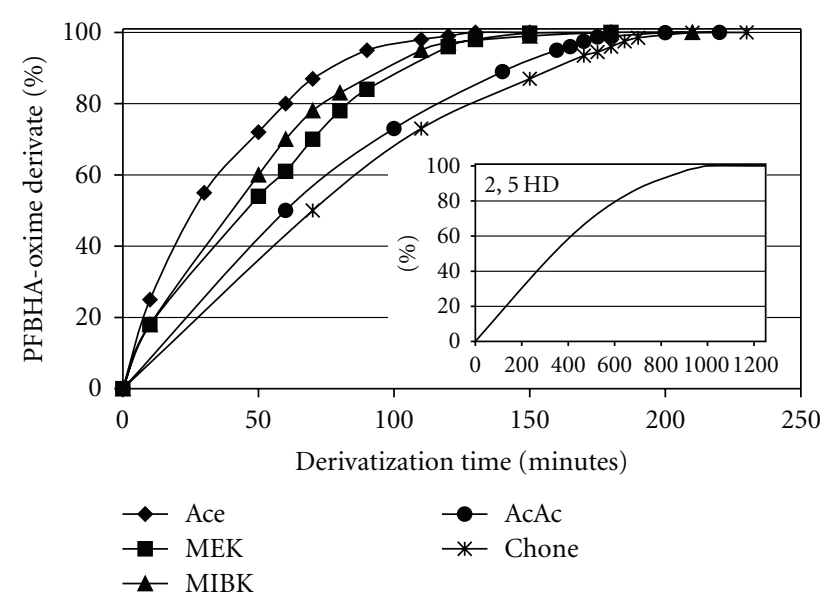

FIgURe 3: Derivatization time for ketone-PFBHA-oximes at $25^{\circ} \mathrm{C}$.

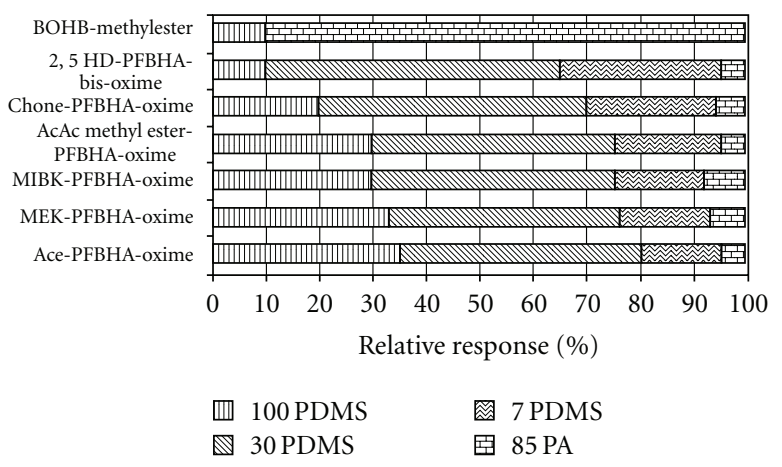

FIGURE 4: Extraction efficiency for liquid phase SPME fibers.

compounds were examined. The agitation of the solution can strongly improve the SPME extraction process and the equilibrium times increased with increasing molecular mass of the analytes (Table 1). Since the extraction with SPME is based on an equilibrium between the analyte concentrations in the liquid and fiber coating, it is not necessary to reach an absorption equilibrium for quantitative analysis if the absorption time and mixing conditions are held constant throughout the experiment. Thus, a 5-min extraction time was employed because this yielded sufficient extraction and excellent precision data (Table 2). Except for Ace-PFBHA-oxime, with a single chromatographic peak, for the other ketone-PFBHA-oximes the formation of a double peak, corresponding to syn- and anti-isomer, was observed (Figure 5) and the total area of the two peaks was used for their quantitative determination. The PFBHA by onsample derivatization was so chosen for this work, because it is commercially avaiable and, under these conditions, the method allows for the selective detection of ketones at a very low levels without interferences.

3.1.2. Carboxylic Functional Groups SPME-Derivatization. Several reagents can be found in the literature for the derivatisation of carboxylic compounds for allowing different derivatisation approaches: 1-pyrenyldiazomethane, 1(pentafluorphenyl) diazomethane, diazomethane, 2,3,4,5,6,pentafluorobenzyl bromide, BSTFA, or isobutyl chloroformate $[32,33]$. The addition of modifiers, such as ion-pairing agents which activate the analytes during derivatization in the injection port, increases esterification yields [34]. For carboxylic functional groups of AcAc and $\mathrm{BOHO}$ the authors confirm the same critical factors more than those observed by the employed of the derivatizations above indicated, (i) very expensive reagents; (ii) presence of moisture led to production of artefacts; (iii) effect of the injector temperature on the efficiency of derivatization; (iv) capability to derivatize only the aliphatic molecule with low molecular weight; and (v) damaging of the coating of the fiber after only few derivatizations. In this work, a new and different approach to this problems is implemented by the use of MTBSTFA and of TMO, as a silylating and methylating agents for $\mathrm{BOHO}$ and AcAc urinary determination.

MTBSTFA as a TBDMS derivatizing agents

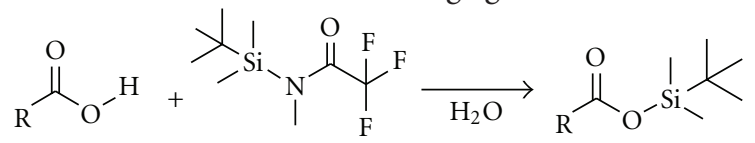

was used in GC analysis of amino acids and in GC-MS analysis of fatty acids, ketone bodies, and hydroxylated fluorenes, and it was shown that TBDMS derivatives were thermally stable and had favourable fragmentations upon EI ionization $[35,36]$. These spectra were simple and gave intense fragment ion peaks (BOHO-, m/z 275 and AcAcTBDMS, and $\mathrm{m} / \mathrm{z} 273)$, corresponding to the $[\mathrm{M}-57]^{+}$ion due to the loss of a tert-butyl fragment from the molecular ion. It was found that the intensity due the base peaks of BOHO-/AcAc-TBDMS was about five times higher than that of BOHO-/AcAc-trimethylsilyl (TMS) even if the TBDMS derivatives had later eluting times than the corresponding TMS derivatives. For SPME on-fiber derivatization, the PA fiber was selected as the most appropriate since the coating of PDMS fiber was stripped off after only 3-5 derivatizations by the MTBSTFA. So, the effects of time, temperature and volume of urine, and derivatizating reagent for automated and high-throughput quantitative analysis were evaluated. An excellent SPME extraction sensitivity for the urinary $\mathrm{BOHO}$ and AcAc was generally achieved by immerging the fiber in the diluted urine $(1: 5 \mathrm{v} / \mathrm{v})$ with temperaturecontrolled agitation $\left(50^{\circ} \mathrm{C}\right.$ and $\left.500 \mathrm{rpm}\right)$. Dilution of the urine with distilled water reduces the sensitivity of the method but increases the precision and the fiber lifetime. The better results were obtained with DI times up to 2 hours. Moreover, since the reduction in vial diameter by a factor of 3 resulted in an order of magnitude decrease in extraction time, where $t$, the average time of the diffusion through the aqueous layer is expected to be proportional to the square of the migration distance, $x$, and inversely proportional to the diffusion coefficient in $D_{\text {water }}$,

$$
t=\frac{x^{2}}{2 D}
$$




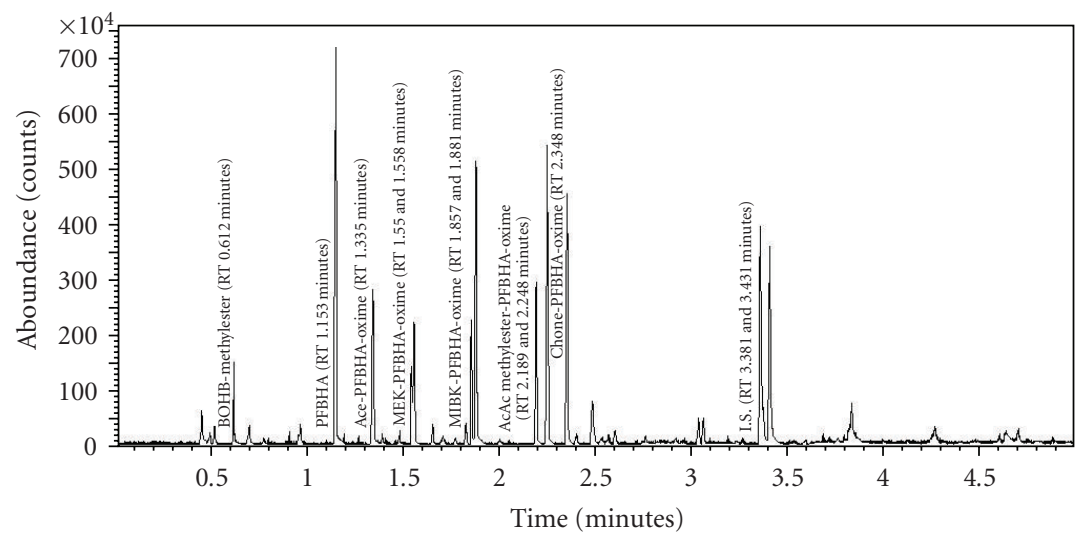

(a)

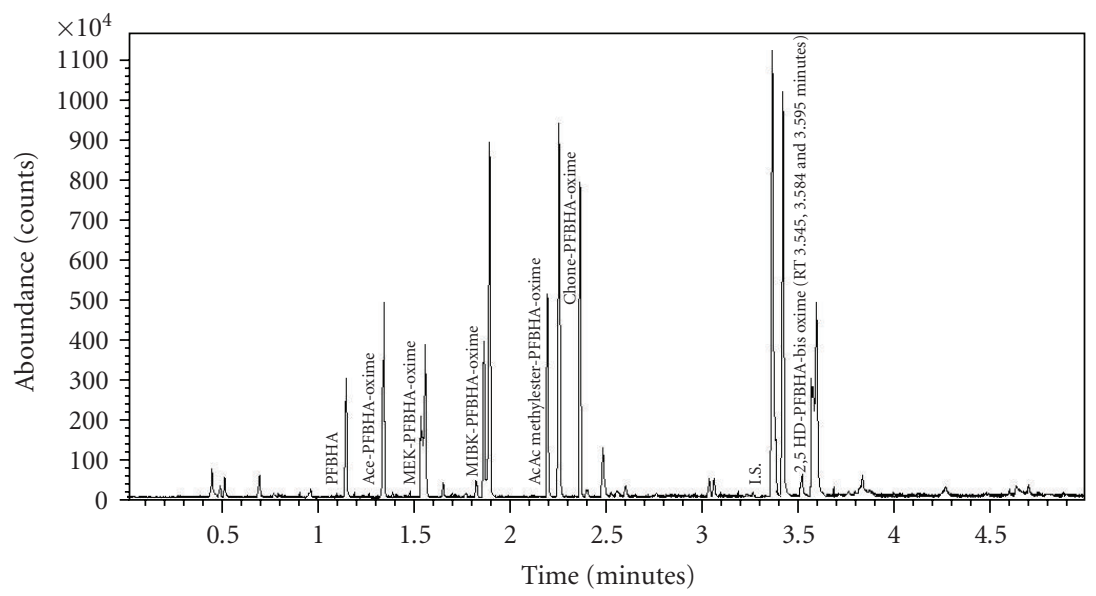

(b)

FIgURE 5: Fast GC/MS chromatogram of the organic ketone derivatives by EI (Figure 5(a)) and NCI (Figure 5(b)) mode.

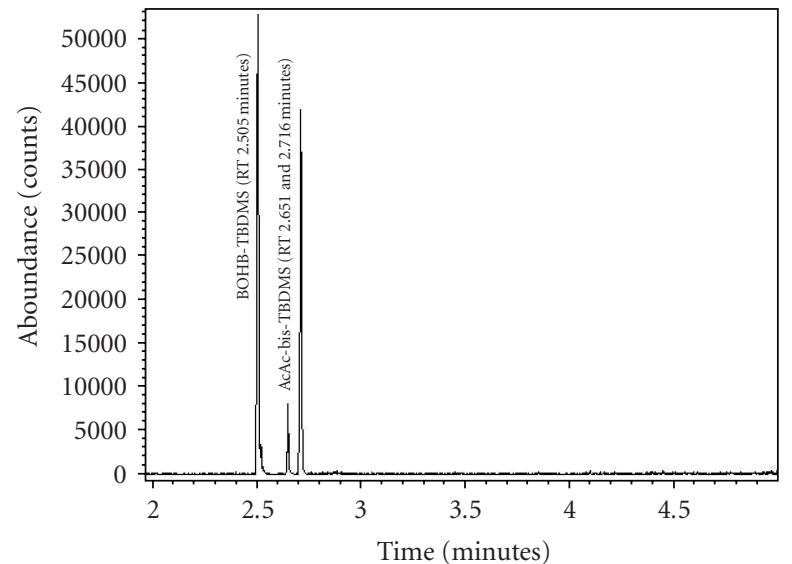

Figure 6: Fast GC/MS chromatogram of the BOHO-/AcAcTBDMS by EI mode.

for high-throughput analysis $2 \mathrm{~mL}$ vial was used instead of $10 \mathrm{~mL}$ vial [37]. For on-fiber derivatization low and high values for three variables $\left(20-100 \mu \mathrm{L}\right.$ MTBSTFA, $25-50^{\circ} \mathrm{C}$, and 10-60 minutes) were selected on the basis of previously reported results [38]. The volume of MTBSTFA and the derivatization time did not show significant effects and so they were fixed to $20 \mu \mathrm{L}$ and 15 minutes, respectively. In order to avoid contamination problems between consecutive samples, on-fiber derivatization was performed in different $2 \mathrm{~mL}$ vials and the fibers were additionally desorbed after the analysis during 1 minute at $300^{\circ} \mathrm{C}$. In spite of these slow kinetics rates, the extraction and derivatization time were limited to 15 minutes to speed up sample preparation (Figure 6). Obviously, the corresponding decrease in the sensitivity of the method was assumed.

Trialkyloxonium ions (Meerwein salts), $\mathrm{R}_{3} \mathrm{O}^{+}$, with various counterions such as $\mathrm{SbF}_{6}{ }^{-}, \mathrm{BF}_{4}{ }^{-}, \mathrm{SbCl}_{6}{ }^{-}$, and $\mathrm{PF}_{6}{ }^{-}$ are excellent alkylating agents for nucleophiles containing heteroatoms such as $\mathrm{N}, \mathrm{O}$, or S [39]. With TMO a methyl group of the oxonium ion reacts with the anion of the carboxylic functional groups to form the methyl ester:

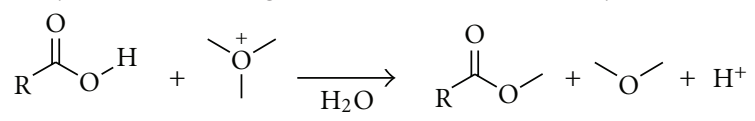

The Fast GC/MS was used for verifing conversion of the $\mathrm{BOHO}$ and AcAc into the corresponding methylester and methylester-PFBHA-oxime derivative. Briefly, the urine was 
TABle 1: Physical chemical properties [17-22] of organic ketones and related partition coefficient. $(T=298 K, \mathrm{R}=8.20575 *$ $\left.10^{-5} \mathrm{~m}^{3} \mathrm{~atm} \mathrm{~mol}^{-1} \mathrm{~K}^{-1}\right)$.

\begin{tabular}{|c|c|c|c|c|c|c|c|c|c|}
\hline & $\begin{array}{l}\text { BOHB- } \\
\text { methylester }\end{array}$ & $\begin{array}{l}\text { Ace- } \\
\text { PFBHA- } \\
\text { oxime }\end{array}$ & $\begin{array}{l}\text { MEK- } \\
\text { PFBHA- } \\
\text { oxime }\end{array}$ & $\begin{array}{l}\text { MIBK- } \\
\text { PFBHA- } \\
\text { oxime }\end{array}$ & $\begin{array}{l}\text { AcAc- } \\
\text { methylester- } \\
\text { PFBHA- } \\
\text { oxime }\end{array}$ & $\begin{array}{l}\text { CHone- } \\
\text { PFBHA- } \\
\text { oxime }\end{array}$ & $\begin{array}{l}2,5 \mathrm{HD} \\
\text { bis- } \\
\text { PFBHA- } \\
\text { oxime }\end{array}$ & AcAc & ВOHB \\
\hline Boiling Point $\left({ }^{\circ} \mathrm{C}\right)$ & 190 & 306 & 329 & 374 & 405 & 369 & 663 & n.d. & n.d. \\
\hline Melting Point $\left({ }^{\circ} \mathrm{C}\right)$ & 40 & 107 & 118 & 126 & 175 & 177 & 387 & 36 & 46 \\
\hline Density $(\mathrm{g} / \mathrm{mL})$ & 1.31 & 1.59 & 1.54 & 1.45 & 1.65 & 1.50 & 1.67 & n.d. & n.d. \\
\hline $\begin{array}{l}\text { Water Solubility } \\
(\mathrm{mol} / \mathrm{L})\end{array}$ & 0.14 & $6.310^{-18}$ & $2.910^{-18}$ & $9.510^{-19}$ & $4.110^{-19}$ & $2.610^{-19}$ & $1.310^{-35}$ & 9.3 & 9.6 \\
\hline$P_{\text {vap }}(\mathrm{mm} \mathrm{Hg})$ & 112 & 7.26 & 0.21 & 0.039 & 0.005 & 0.042 & $8.310^{-6}$ & 0.218 & $9.710^{-3}$ \\
\hline$\Delta H^{v \mathrm{a}}(\mathrm{kal} / \mathrm{mol})$ & 12449 & 17650 & 18746 & 20950 & 22515 & 20701 & 36754 & n.d. & n.d. \\
\hline$K_{\mathrm{ow}}$ & 14 & 1995 & 6309 & 50118 & 1258 & 12589 & 269 & 0.104 & 0.338 \\
\hline $\begin{array}{l}K_{\mathrm{H}}\left(25^{\circ} \mathrm{C}\right) \text { atm } \\
\mathrm{m}^{3} / \mathrm{mol}\end{array}$ & $5.510^{-4}$ & $8.810^{-4}$ & $2.110^{-3}$ & $2.610^{-3}$ & $9.710^{-5}$ & $4.610^{-6}$ & $5.310^{-8}$ & $3.710^{-10}$ & $3.510^{-11}$ \\
\hline $\begin{array}{l}D_{\text {water }}^{\mathrm{b}}\left(25^{\circ} \mathrm{C}\right) \\
\mathrm{cm}^{2} / \mathrm{sec}\end{array}$ & $8.110^{-6}$ & $5.510^{-6}$ & $5.810^{-6}$ & $5.610^{-6}$ & $5.410^{-6}$ & $5.310^{-6}$ & $4.110^{-6}$ & n.d. & n.d. \\
\hline$D_{\text {air }}{ }^{\mathrm{c}}\left(25^{\circ} \mathrm{C}\right) \mathrm{cm}^{2} / \mathrm{sec}$ & $7.410^{-2}$ & $5.210^{-2}$ & $5.410^{-2}$ & $5.310^{-2}$ & $5.110^{-2}$ & $5.010^{-2}$ & $4.010^{-2}$ & n.d. & n.d. \\
\hline $\mathrm{Y}_{\mathrm{PDMS}(\mathrm{MW} 15000)}\left(25^{\circ} \mathrm{C}\right)$ & 0.0228 & 0.0188 & 0.0259 & 0.0293 & 0.2600 & 0.0237 & 0.5046 & n.d. & n.d. \\
\hline $\begin{array}{l}Y_{\text {PDMS }}(\text { MW 30000) } \\
\left(25^{\circ} \mathrm{C}\right)\end{array}$ & 0.0842 & 0.00955 & 0.0131 & 0.0149 & 0.1322 & 0.0120 & 0.2584 & n.d. & n.d. \\
\hline $\begin{array}{l}Y_{\text {PDMS }}(\text { MW 36900) } \\
\left(25^{\circ} \mathrm{C}\right)\end{array}$ & 0.0092 & 0.00769 & 0.0106 & 0.0120 & 0.1065 & 0.0096 & 0.2085 & n.d. & n.d. \\
\hline $\begin{array}{l}Y_{\text {PDMS }}\left(M W 1_{15000)}\right. \\
\left(50^{\circ} \mathrm{C}\right)\end{array}$ & 0.0204 & 0.01354 & 0.0186 & 0.0215 & 0.1452 & 0.0181 & 0.2323 & n.d. & n.d. \\
\hline $\begin{array}{l}\mathrm{Y}_{\mathrm{PDMS}}(\mathrm{MW} 30000) \\
\left(50^{\circ} \mathrm{C}\right)\end{array}$ & 0.0102 & 0.00686 & 0.0094 & 0.0091 & 0.0738 & 0.0091 & 0.1189 & n.d. & n.d. \\
\hline $\begin{array}{l}\text { Y PDMS (MW 36900) } \\
\left(50^{\circ} \mathrm{C}\right)\end{array}$ & 0.0082 & 0.00552 & 0.0076 & 0.0088 & 0.0587 & 0.0074 & 0.0960 & n.d. & n.d. \\
\hline$K_{1}\left(=K_{\mathrm{ow}} / K_{2}\right)$ & 636 & $3.310^{4}$ & $7.110^{4}$ & $4.210^{5}$ & $4.210^{5}$ & $4.1110^{6}$ & $1.310^{8}$ & n.d. & n.d. \\
\hline$K_{1}($ from $(4))$ & 585 & $1.810^{4}$ & $2.710^{4}$ & $1.110^{5}$ & $1.310^{5}$ & $4.4210^{6}$ & $1.910^{8}$ & n.d. & n.d. \\
\hline$K_{1}($ from $(5))$ & 483 & $2.910^{4}$ & $5.110^{4}$ & $2.910^{5}$ & $3.310^{5}$ & $5.110^{6}$ & $1.710^{8}$ & n.d. & n.d. \\
\hline$T_{\mathrm{e}}(\min )$ DI-SPME & 7 & 25 & 25 & 30 & 35 & 30 & 65 & 120 & 120 \\
\hline
\end{tabular}

${ }^{a}$ Estimated diffusion coefficient in water $(1 \mathrm{~atm}, 298 \mathrm{~K})$ by Hayduk and Laudie method. ${ }^{\mathrm{b}}$ Estimated diffusion coefficient in air ( $\left.1 \mathrm{~atm}, 298 \mathrm{~K}\right)$ by Fuller Schettler and Giddings method. ${ }^{\mathrm{c} C a l c u l a t e d ~ v a p o r i z a t i o n ~ e n t h a l p i e s ~(298 ~ K) ~ b y ~ H i l d e b r a n d ~ e q u a t i o n ~}\left(\Delta H v=-2950+23.7 \mathrm{Teb}+0.020 T_{\mathrm{eb}} 2\right)$.

treated in the same manner as indicated in Experimental data and extracted with $3 \mathrm{~mL}$ of hexane. After the extraction, the solvent was evaporated to dryness and the residue was dissolved in $0.2 \mathrm{~mL}$ of hexane for GC analysis. Conversion of AcAc and BOHO was carried out using calibration graph from known amounts of BOHO-methylester and AcAc-methylester-PFBHA-oxime and data gave an indication of the yield of the derivatisation reaction more than 95\%.

3.1.3. Selection of SPME Fiber. The second objective to the verify the ability of DI-SPME technique to determine the seven urinary ketones. The absortive liquid coatings PDMS and PA were choice for sampling of a very complex matrix as to urine, because there is no competition between analytes and so no labeled compounds were used as internal standards. The stationary phases were evaluated as predominant characteristic affecting the absorption. For PDMS, where 100,30 , and $7 \mu \mathrm{m}$ thickness fiber coatings were commercially available, better result was obtained with $30 \mu \mathrm{m}$ PDMS fiber, accorded with what is indicated from the theory where thin thickness has more efficient extraction for high molecular weight in fast equilibrium time. Since the polar coating PA has better affinity toward methylester than nonpolar PDMScoated, PA fiber was employed for BOHO determination (Figure 4). A decrease in the coating thickness by a factor 3 from $100 \mu \mathrm{m}$ to about $30 \mu \mathrm{m}$ results in a ca. 3 -fold decrease in extraction time, as well as the extraction time profiles are dramatically affected by the stirring rate (ca. 7-fold). The extraction time in the unagitated case is limited by the transport of analyte in the aqueous phase. A decrease in the diffusion coefficient of the analyte in water by an order of magnitude produced about an order of magnitude increase in equilibration time as discussed by Louch et al. [37].

Moreover, the equilibrium and kinetics of the seven ketones versus SPME fiber with liquid coating were investigated theoretically. Table 1 illustrated the physicochemical 
TABLE 2: Summary of the method performance.

\begin{tabular}{lcccc}
\hline & $\begin{array}{c}\text { Range } \\
(\mathrm{mg} / \mathrm{L})\end{array}$ & $\begin{array}{c}\text { Slope } \\
(\mathrm{m})\end{array}$ & $\begin{array}{c}\text { Intercepts } \\
(\mathrm{b})\end{array}$ & $\begin{array}{c}\text { LOD } \\
(\mathrm{mg} / \mathrm{L})\end{array}$ \\
\hline BOHB-methylester (EI, quantification ion $\mathrm{m} / \mathrm{z}$ 43) & $10-500$ & $0.00122 \pm 0.000014$ & $0.000403 \pm 0.000153$ & 0.49 \\
Ace-PFBHA-oxime (NCI, quantification ion $\mathrm{m} / \mathrm{z}$ 178) & $0.1-10$ & $0.106050 \pm 0.000679$ & $0.002073 \pm 0.000778$ & 0.0294 \\
MEK-PFBHA-oxime (NCI, quantification ion $\mathrm{m} / \mathrm{z}$ 178) & $0.025-4.0$ & $0.28966 \pm 0.003915$ & $0.00084 \pm 0.00009$ & 0.0033 \\
MIBK-PFBHA-oxime (NCI, quantification ion $\mathrm{m} / \mathrm{z}$ 178) & $0.2-4.0$ & $0.186707 \pm 0.002173$ & $0.00058 \pm 0.000128$ & 0.004 \\
Chone-PFBHA-oxime (NCI, quantification ion $\mathrm{m} / \mathrm{z}$ 178) & $0.05-4.0$ & $0.320697 \pm 0.006647$ & $0.000757 \pm 0.00021$ & 0.0032 \\
2,5 HD bis-PFBHA-oxime (NCI, quantification ion $\mathrm{m} / \mathrm{z}$ 178) & $0.01-1.0$ & $0.34784 \pm 0.007879$ & $0.001147 \pm 0.000423$ & 0.0049 \\
AcAc-methylester-PFBHA-oxime (NCI, quantification ion $\mathrm{m} / \mathrm{z}$ 178) & $0.5-50$ & $0.024497 \pm 0.000948$ & $0.002573 \pm 0.001285$ & 0.1755 \\
BOHB-TBDMS (EI, quantification ion $\mathrm{m} / \mathrm{z}$ 275) & $250-1000$ & $0.000193 \pm 0.000005$ & $0.007547 \pm 0.000638$ & 43.46 \\
AcAc-TBDMS (EI, quantification ion $\mathrm{m} / \mathrm{z}$ 273) & $250-1000$ & $0.00035 \pm 0.000016$ & $0.00434 \pm 0.000979$ & 16.15 \\
\hline
\end{tabular}

constants of the ketones-oxime-/methyl ester-ketone-oximederivatives and PDMS obtained by literature [17-22] to anticipate trends in sampling extraction. For $\mathrm{BOHB}$ and AcAc the derivatisations were also performed on-fiber after the preconcentration step by DI-SPME with PA liquid phase, and so kinetics of the underivatised BOHB and AcAc versus SPME coating were evaluated.

Because of the properties liquid coating, which is applied in DI-SPME analysis, the extraction obeys the rules of liquidliquid equilibrium

$$
n=\frac{C_{0} V_{1} V_{2} K}{K V_{1}+V_{2}}
$$

where $K$ is the partition constant SPME fiber liquid polymeric coating/sample, $C_{0}$ is the initial concentration of the analyte in the aqueous solution, $V_{1}$ and $V_{2}$ are the volumes of the coating and the aqueous solution, in the equilibrium concentration of the analyte in the aqueous matrix. However, SPME is an equilibrium extraction but not an exhaustive extraction. Thus, it is also evident that DISPME will mainly have a low or very low recovery with small $K_{1}\left(<1.085 \cdot 10^{4}\right)$, high Henry's constant $\left(>34 \mathrm{~atm} \mathrm{~cm}^{3} / \mathrm{mol}\right)$, and high hydrophobicity (octanol-water partitioning, $K_{\text {ow }}$ up to 81.2) values. As indicated in Table $1 K_{\text {ow }}$ is a good estimated of $K$, however, the correlation has to be confirmed for the group of substances from a number of investigators [40].

$K$ values of the analytes are often very close to the gas phase partition coefficient/aqueous matrix partition coefficient $\left(K_{2}=K_{H} / R T\right)$ and to the SPME coating/gas phase partition coefficient $\left(K_{1}\right) ; K=K_{2} \cdot K_{1}$, where it is more practical to say that both $K_{1}$ and $K_{2}$ values allowed to know in advance whether or not the SPME method offers the advantages. The linear relationship with solute activity coefficient and LTPRI [41], as in (4) and (5), respectively, can be used further to estimate the $K_{1}$ values

$$
\log K_{1}=\frac{a}{T}+b,
$$

where $a=\Delta H^{v} / 2.303 R$ and $b=\left[\log \left(R T / \gamma P_{\text {vap }}\right)-\right.$ $\left.\Delta H^{\nu} / 2.303 R^{*}\right] ; \Delta H^{\nu}$ (J/moli) is the analyte heat of vaporization, $R(8.314 \mathrm{~J} / \mathrm{moli} \mathrm{K})$ is the gas constant, $T(\mathrm{~K})$ is the sampling temperature, $\gamma$ solute activity coefficient, $P_{\text {vap }}(\mathrm{Pa})$ is the vapour pressure, and $T^{*}$ is the known temperature of coefficient,

$$
\log K_{1}=0.0042 \cdot \text { LTPRI }-0.188 .
$$

The LTPRI $\left.=100 \cdot\left(T_{R(A)}-T_{R(n)} / T_{R(n+1)}-T_{R(n)}\right)+100 \cdot n\right)$ was experimentally calculated by PDMS capillary column where, $T_{R(A)}$ is the analyte retention time, $T_{R(n)}$ is the retention time of $n$-alkane eluting directly before $T_{R(A)}, T_{R(n+1)}$ is the retention time of the $n$-alkane eluting directly after $T_{R(A)}$, and $n$ is the number of carbon atoms for $T_{R(n)}$. However, this is virtually impossible, at least for (5), as no chromatographic columns with PA phases are commercially available to date.

The significant correlation found in (Table 1) seems to indicate the evaluated $K_{1}$ values of seven substances were essentially identical with experimental procedures and this alternative theoretical approach could allow to simplify the use of SPME for qualification of compounds without the need for fiber calibration.

3.2. Choice of Fast GC/NCI-EI/MS. Accordingly, we developed a methodology where the properties of SPME technique after on-sample and on-fiber derivatisation were coupled to the quantitative determination by Fast GC/NCIEI/MS. So, the third objective was the effective chromatographic separation of the seven substances in the minimum time and the investigation of the structurally informative MS fragmentation pattern.

In this investigation, the GC analysis of ketones-oxime/methyl ester-ketone-oxime-derivatives is carried out in less than 3.50 minutes and 2 minutes between two different chromatographic runs, with a speed gain of almost 8 times in comparison with traditional GC procedure to maintain sufficient resolving power for separation of the compounds of interest.

Regards to PFBHA-oxime-derivates the mass spectrum (Table 3 ) shows the advantages in using NCI rather than the usual EI, that is, more detailed information about the molecular structure and not only a conspicuous increase in sensibility as due to a sensible lowering of the chemical background (chemical noise). As a matter of fact, the EI rarely allows to detect the molecular peak of the PFBHAoxime-ketones, the only peak detected often being that of $\mathrm{m} / \mathrm{z} 181$, related to the PFB portion. With MS detector which 
TABLE 3: PFBHA-oxime-derivates NCI/MS spectrum.

\begin{tabular}{|c|c|c|c|}
\hline Name & Structure formula and GC/NCI/MS spectra & $\begin{array}{c}\text { Fragment ions from } \\
\text { simple cleavages }\end{array}$ & $\begin{array}{l}\text { Fragment ions from } \\
\text { rearrangement cleavages }\end{array}$ \\
\hline $\begin{array}{l}\text { Ace-PFBHA- } \\
\text { oxime }\end{array}$ & 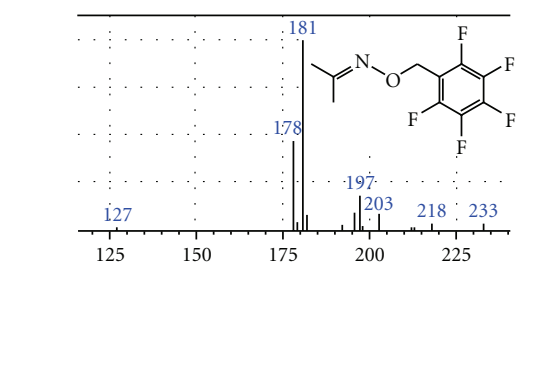 & il & $\begin{array}{l}{[\mathrm{M}-\mathrm{HF}]=233} \\
{\left[\mathrm{M}-\mathrm{HF}-\mathrm{CH}_{3}\right]=218} \\
\left.=197=2 \mathrm{CH}_{3}\right]=203\end{array}$ \\
\hline $\begin{array}{l}\text { MEK-PFBHA- } \\
\text { oxime }\end{array}$ & 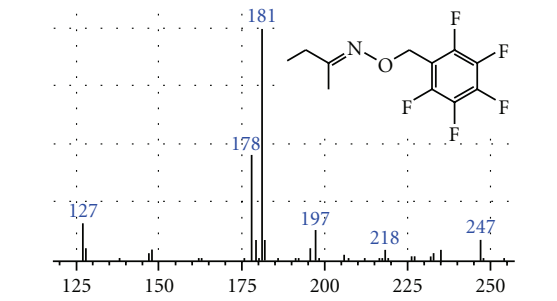 & $\begin{array}{l}\longrightarrow \mathrm{m} / \mathrm{z} 197 \\
\longrightarrow \mathrm{m} / \mathrm{z} 181\end{array}$ & $\begin{array}{l}{[\mathrm{M}-\mathrm{HF}]=247} \\
{\left[\mathrm{M}-\mathrm{HF}-\mathrm{C}_{2} \mathrm{H}_{5}\right]=218} \\
=197,178 \text { (fragments shown above) }\end{array}$ \\
\hline $\begin{array}{l}\text { MIBK-PFBHA- } \\
\text { oxime }\end{array}$ & 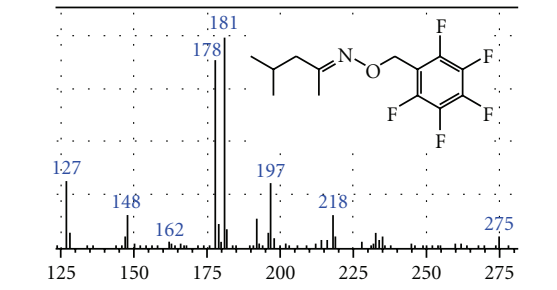 & $\rightarrow \mathrm{m} / \mathrm{z} 197$ & $\begin{array}{l}{[\mathrm{M}-\mathrm{HF}]=275} \\
{\left[\mathrm{M}-\mathrm{HF}-\mathrm{C}_{4} \mathrm{H}_{9}\right]=218} \\
=197,178 \text { (fragments shown above) }\end{array}$ \\
\hline $\begin{array}{l}\text { CHone- } \\
\text { PFBHA- } \\
\text { oxime }\end{array}$ & 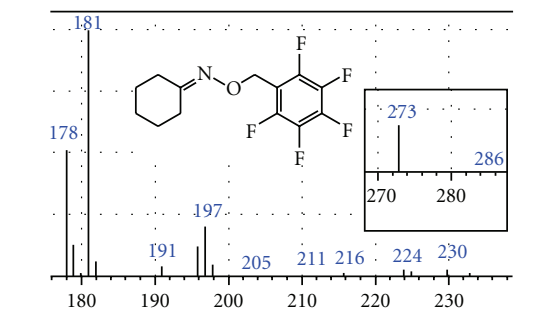 & $\mathrm{m}_{\mathrm{m} / \mathrm{z} 181}^{\mathrm{m} / \mathrm{z} 197}$ & $\begin{array}{l}{[\mathrm{M}-\mathrm{HF}]=273} \\
=197,178 \text { (fragments shown above) }\end{array}$ \\
\hline $\begin{array}{l}\text { AcAc- } \\
\text { PFBHA- } \\
\text { oxime- } \\
\text { methylester }\end{array}$ & 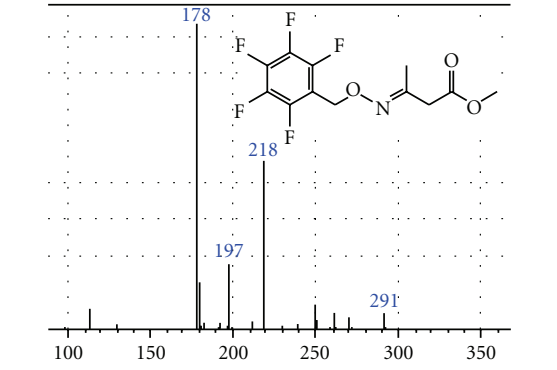 & $\underset{\mathrm{F}}{\longrightarrow \mathrm{m} / \mathrm{z} 181}$ & $=291$ \\
\hline $\begin{array}{l}2,5 \text { HD- } \\
\text { PFBHA- } \\
\text { bis oxime }\end{array}$ & 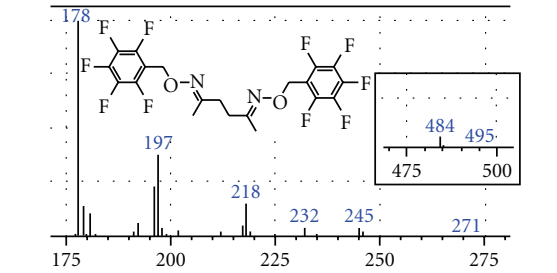 & m m/z 197 & $\begin{array}{l}{[\mathrm{M}-\mathrm{HF}]=484} \\
=218,197,178 \text { (fragments shown } \\
\text { above) }\end{array}$ \\
\hline
\end{tabular}


registers selected negative ions generated in the ion source by chemical ionization, it is also possible to detect not only the signals related to PBF $(\mathrm{m} / \mathrm{z} 197,196,181,178)$, but also the [M-HF] signal. Moreover, this analysis allows to distinguish a methyl-ketone from another kind of ketones, thanks to the presence of anion [42]:

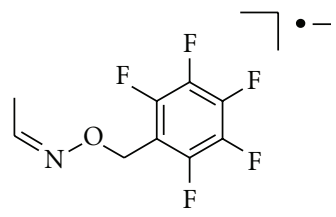

3.3. Automation of the Procedure. This technology allows to analyze 96 samples in 24 hours, for a total 627 determinations/day. Since BOHO and AcAc the on-fiber derivatization method was better for less analysis time than HS-SPME of BOHO-methylester and DI-SPME for AcAc-methylesterPFBHA-oxime, for fully automated analysis, priority samples when high Ace concentrations can be added to the system at any point of the analysis sequence of $\mathrm{BOHO} / \mathrm{AcAc}-\mathrm{TBDMS}$. The quality of the Fast GC/MS approach allowed for excellent resolution, even with very short analysis time, to resolve the analytes of interest from similar compounds that would interfere with the assay.

In light of what indicated above the authors present the final results in Table 2 . The resulting calibration curves were linear, in the investigated range for all the considerated ketones, with correlation coefficients $>0.998$. The precision of the assay (reported as a coefficient of variation, C.V.\%), estimated both as withinsession and as intersession repeatability resulted in the range 2.53-6.98 and 1.14-5.32\%, respectively. Accuracy was within 15\% of the theoretical concentration, in line with the requirement of US Food and Drug Administration for the bioanalytical methods validation. To demonstrate the applicability of the method to urinary samples, the content of these compounds in human urines $(n=20)$ of no-exposed, no-smoking subject was analyzed. The urinary excretion of MEK, MIBK, Chone and free 2,5 HD in control subjects was in the range 1.2$5.0 \mu \mathrm{g} / \mathrm{L}$, while Ace, $\mathrm{BOHB}$, and AcAc were excreted at a high concentration $(0.11-0.38 \mathrm{mg} / \mathrm{L})$. Concentrations of BOHO 183-2300 mg/L), AcAc (50-872 mg/L), and Ac (10$431 \mathrm{mg} / \mathrm{L})$ in urine test stick positive $($ score +-++++$)$ were obtained.

\section{Conclusion}

This paper reports the first contribution to the automated and high-throughput analysis of seven ketones in urine by SPME/MS system. Our data suggest that automated SPME extraction coupled with Fast GC/NCI-EI/MS may be a viable alternative for ketones analyses in human urine. A noninvasive method has been developed for occupational health and diagnosis of ketoacidoses where it is critically important to rapidly differentiate between relative benign and life-threatening conditions (i.e., Point of Care Testing). The accurate determination of the ketone body ratio is important in the diagnosis of diabetes mellitus and of order metabolic disorders. Clinicians are encouraged to consider and utilize this noninvasive assay to guide early clinical diagnosis and management of metabolic acidosis and works are in progress along this line.

So, the introduction of dedicated, automated, and robotic systems allowed a friendly use of MS apparatus for high-throughput screening so as to reduce the costs of the monitoring campaigns. The specific MS instrumentation suitable for this aim, such as the changeover from NCI to EI modes and the automation of the preparation procedure with MFX, that allowed the change of the fiber by robotic device, allowed a friendly use of MS apparatus with a number of advantages including reduced analyst time both for routine analysis and method development, and greater reproducibility.

\section{References}

[1] L. Perbellini and C. Minoia, "Escrezione dei solventi," in Monitoraggio Ambientale e Biologico dell'Esposizione Professionale a Xenobiotici: Solventi II, pp. 71-81, Morgan Edizioni Tecniche, Milan, Italy, 2001.

[2] T. Kawai, Y. Miyama, S. Horiguchi, et al., "Possible metabolic interaction between hexane and other solvents co-exposed at sub-occupational exposure limit levels," International Archives of Occupational and Environmental Health, vol. 73, no. 7, pp. 449-456, 2000.

[3] L. Carmant, "Assessing ketosis: approaches and pitfalls," Epilepsia, vol. 49, supplement 8, pp. 20-22, 2008.

[4] M. J. Prieto, D. Marhuenda, J. Roel, and A. Cardona, "Free and total 2,5-hexanedione in biological monitoring of workers exposed to n-hexane in the shoe industry," Toxicology Letters, vol. 145, no. 3, pp. 249-260, 2003.

[5] M. Vanelli, G. Chiari, and C. Capuano, "Cost effectiveness of the direct measurement of 3- $\beta$-hydroxybutyrate in the management of diabetic ketoacidosis in children," Diabetes Care, vol. 26, no. 3, p. 959, 2003.

[6] J. G. M. van Engelen, S. Kezić, W. de Haan, J. J. G. Opdam, and F. A. de Wolff, "Determination of 2,5-hexanedione, a metabolite of $n$-hexane, in urine: evaluation and application of three analytical methods," Journal of Chromatography B, vol. 667, no. 2, pp. 233-240, 1995.

[7] A. A. Matin, R. Maleki, M. A. Farajzadeh, K. Farhadi, R. Hosseinzadeh, and A. Jouyban, "Headspace SPME-GC method for acetone analysis and its biomedical application," Chromatographia, vol. 66, no. 5-6, pp. 383-387, 2007.

[8] K. Kobayashi, M. Okada, Y. Yasuda, and S. Kawai, "A gas chromatographic method for the determination of acetone and acetoacetic acid in urine," Clinica Chimica Acta, vol. 133, no. 2, pp. 223-226, 1983.

[9] S. Kezić and A. C. Monster, "Determination of 2,5hexanedione in urine and serum by gas chromatography after derivatization with O-(pentafluorobenzyl)hydroxylamine and solid-phase extraction," Journal of Chromatography, vol. 563, no. 1, pp. 199-204, 1991.

[10] S. Ghittori, M. Imbriani, G. Pezzagno, and E. Capodaglio, "The urinary concentration of solvents as a biological indicator of exposure: proposal for the biological equivalent exposure limit for nine solvents," American Industrial Hygiene Association Journal, vol. 48, no. 9, pp. 786-790, 1987. 
[11] S. Strassnig, M. Gfrerer, and E. P. Lankmayr, "Microwaveassisted derivatization of 2,5-hexanedione in urine: evaluation using GC-MS and GC-ECD," Journal of Chromatography B, vol. 813, no. 1-2, pp. 151-158, 2004.

[12] S. Yamato, K. Kobayashi, K. Ebara, K. Shimada, and S. Ohta, "High performance liquid chromatographic determination of acetoacetate by post-column derivatization with $\mathrm{p}$ nitrobenzene diazonium fluoroborate," Biological and Pharmaceutical Bulletin, vol. 26, no. 4, pp. 397-400, 2003.

[13] A. Pysanenko, T. Wang, P. Španěl, and D. Smith, "Acetone, butanone, pentanone, hexaeone and heptanone in the headspace of aqueous solution and urine studied by selected ion flow tube mass spectrometry," Rapid Communications in Mass Spectrometry, vol. 23, no. 8, pp. 1097-1104, 2009.

[14] S. W. Smith, A. F. Manini, T. Szekely, and R. S. Hoffman, "Bedside detection of urine $\beta$-hydroxybutyrate in diagnosing metabolic acidosis," Academic Emergency Medicine, vol. 15, no. 8, pp. 751-756, 2008.

[15] P. Q. Tranchida, M. L. Presti, R. Costa, P. Dugo, G. Dugo, and L. Mondello, "High-throughput analysis of bergamot essential oil by fast solid-phase microextraction-capillary gas chromatography-flame ionization detection," Journal of Chromatography A, vol. 1103, no. 1, pp. 162-165, 2006.

[16] J. Handley and C. M. Harris, "Great ideas of a decade," Analytical Chemistry, vol. 73, no. 23, pp. 660-666, 2001.

[17] B. E. Poling, J. M. Prausnitz, and J. P. O'Connell, The Properties of Gases and Liquids, McGraw-Hill, New York, NY, USA, 2001.

[18] L. H. Nelken, "Densities of vapors, liquids and solids," in Handbook of Chemical Property Estimation Methods, W. J. Lyman, W. F. Reehl, and D. H. Rosenblatt, Eds., chapter 19, American Mathematical Society, Providence, RI, USA, 1990.

[19] C. F. Grain, "Vapor pressure," in Handbook of Chemical Property Estimation methods, W. J. Lyman, W. F. Reehl, and D. H. Rosenblatt, Eds., chapter 14, American Mathematical Society, Providence, RI, USA, 1990.

[20] E. J. Baum, Chemical Property Estimation, Theory and Application, CRC Press, Boca Raton, Fla, USA, 1998.

[21] Aa. Fredenslund and J. M. Sørensen, "Group contribution estimation methods," in Models for Thermodynamic and Phase Equilibria Calculations, S. S. Sandler, Ed., chapter 4, Marcel Dekker, New York, NY, USA, 1993.

[22] H. Destaillats and M. J. Charles, “Henry's law constants of carbonyl-pentafluorobenzyl hydroxylamine (PFBHA) derivatives in aqueous solution," Journal of Chemical and Engineering Data, vol. 47, no. 6, pp. 1481-1487, 2002.

[23] J. C. Miller and J. N. Miller, Statistics for Analytical Chemistry, vol. 4, Ellis Horwood, New York, NY, USA, 1984.

[24] X. Duan, D. Zhong, and X. Chen, "Derivatization of $\beta$ dicarbonyl compound with 2,4- dinitrophenylhydrazine to enhance mass spectrometric detection: application in quantitative analysis of houttuynin in human plasma," Journal of Mass Spectrometry, vol. 43, no. 6, pp. 814-824, 2008.

[25] C. N. Konidari, C. D. Stalikas, and M. I. Karayannis, "Gas chromatographic method for the sensitive determination of 2,5-hexanedione using electron capture and mass-selective detection," Analytica Chimica Acta, vol. 442, no. 2, pp. 231239, 2001

[26] E. E. Stashenko, M. A. Puertas, W. Salgar, W. Delgado, and J. R. Martínez, "Solid-phase microextraction with on-fibre derivatisation applied to the analysis of volatile carbonyl compounds," Journal of Chromatography A, vol. 886, no. 1-2, pp. 175-181, 2000.

[27] M. Weisser and G. Spiteller, "Increase of aldehydic compounds derived from plasmalogens in the brain of aged cattle,"
Chemistry and Physics of Lipids, vol. 82, no. 2, pp. 173-178, 1996.

[28] M. Pacenti, S. Dugheri, R. Gagliano-Candela, et al., "Analysis of 2-Chloroacetophenone in air by multi-fiber solid-phase microextraction and fast gas chromatography-mass spectrometry," Acta Chromatographica, vol. 21, no. 3, pp. 379-397, 2009.

[29] G. Pieraccini, G. Bartolucci, M. Pacenti, S. Dugheri, P. Boccalon, and L. Focardi, "Gas chromatographic determination of glutaraldehyde in the workplace atmosphere after derivatization with O-(2,3,4,5,6-pentafluorobenzyl)hydroxylamine on a solid-phase microextraction fibre," Journal of Chromatography A, vol. 955, no. 1, pp. 117-124, 2002.

[30] Q. Wang, J. O'Reilly, and J. Pawliszyn, “Determination of low-molecular mass aldehydes by automated headspace solidphase microextraction with in-fibre derivatisation," Journal of Chromatography A, vol. 1071, no. 1-2, pp. 147-154, 2005.

[31] J. P. Vidal, S. Estreguil, and R. Cantagrel, "Quantitative analysis of cognac carbonyl compounds at the PPB level by GC-MS of their 0-(pentafluorobenzyl amine) derivatives," Chromatographia, vol. 36, pp. 183-186, 1993.

[32] J. Larreta, A. Usobiaga, N. Etxebarria, G. Arana, and O. Zuloaga, "Optimisation of the on-fibre derivatisation of volatile fatty acids in the simultaneous determination together with phenols and indoles in cow slurries," Analytical and Bioanalytical Chemistry, vol. 389, no. 5, pp. 1603-1609, 2007.

[33] M. Pacenti, S. Dugheri, F. Villanelli, et al., "Determination of organic acids in urine by solid-phase microextraction and gas chromatography-ion trap tandem mass spectrometry previous 'in sample' derivatization with trimethyloxonium tetrafluoroborate," Biomedical Chromatography, vol. 22, no. 10, pp. 1155-1163, 2008.

[34] P. L. Neitzel, W. Walther, and W. Nestler, "In-situ methylation of strongly polar organic acids in natural waters supported by ion-pairing agents for headspace GC-MSD analysis," Fresenius' Journal of Analytical Chemistry, vol. 361, no. 3, pp. 318-323, 1998.

[35] N. M. Moreau, S. M. Goupry, J. P. Antignac, et al., "Simultaneous measurement of plasma concentrations and 13Cenrichment of short-chain fatty acids, lactic acid and ketone bodies by gas chromatography coupled to mass spectrometry," Journal of Chromatography B, vol. 784, no. 2, pp. 395-403, 2003.

[36] G. Gmeiner, P. Gärtner, C. Krassnig, and H. Tausch, "Identification of various urinary metabolites of fluorene using derivatization solid-phase microextraction," Journal of Chromatography B, vol. 766, no. 2, pp. 209-218, 2002.

[37] D. Louch, S. Motlagh, and J. Pawliszyn, "Dynamics of organic compound extraction from water using liquid-coated fused silica fibers," Analytical Chemistry, vol. 64, no. 10, pp. 11871199, 1992.

[38] P. Canosa, I. Rodriguez, E. Rubì, and R. Cela, "Optimization of solid-phase microextraction conditions for the determination of triclosan and possible related compounds in water samples," Journal of Chromatography A, vol. 1072, no. 1, pp. 107-115, 2005.

[39] H. M. Liebich and E. Gesele, "Profiling of organic acids by capillary gas chromatography-mass spectrometry after direct methylation in urine using trimethyloxonium tetrafluoroborate," Journal of Chromatography A, vol. 843, no. 1-2, pp. 237245, 1999.

[40] Z. Zhang and J. Pawliszyn, "Headspace solid-phase microextraction," Analytical Chemistry, vol. 65, no. 14, pp. 1843-1852, 1993. 
[41] K. Kolár, M. Ciganek, and J. Malecha, "Air/polymer distribution coefficients for polycyclic aromatic hydrocarbons by solid-phase microextraction sampling," Journal of Chromatography $A$, vol. 1029, no. 1-2, pp. 263-266, 2004.

[42] F. F. Hsu, S. L. Hazen, D. Giblin, J. Turk, J. W. Heinecke, and M. L. Gross, "Mass spectrometric analysis of pentafluorobenzyl oxime derivatives of reactive biological aldehydes," International Journal of Mass Spectrometry, vol. 187, pp. 795812, 1999. 


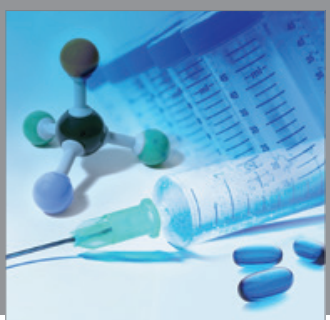

International Journal of

Medicinal Chemistry

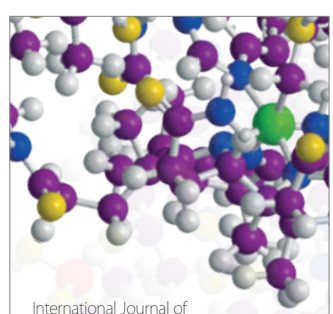

Carbohydrate Chemistry

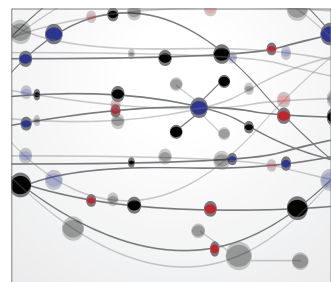

The Scientific World Journal
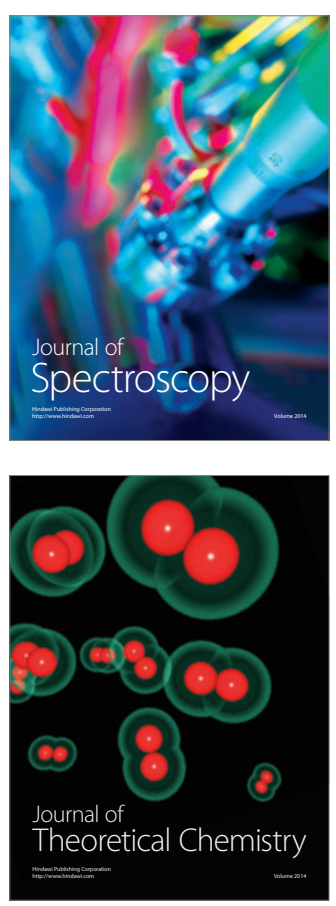
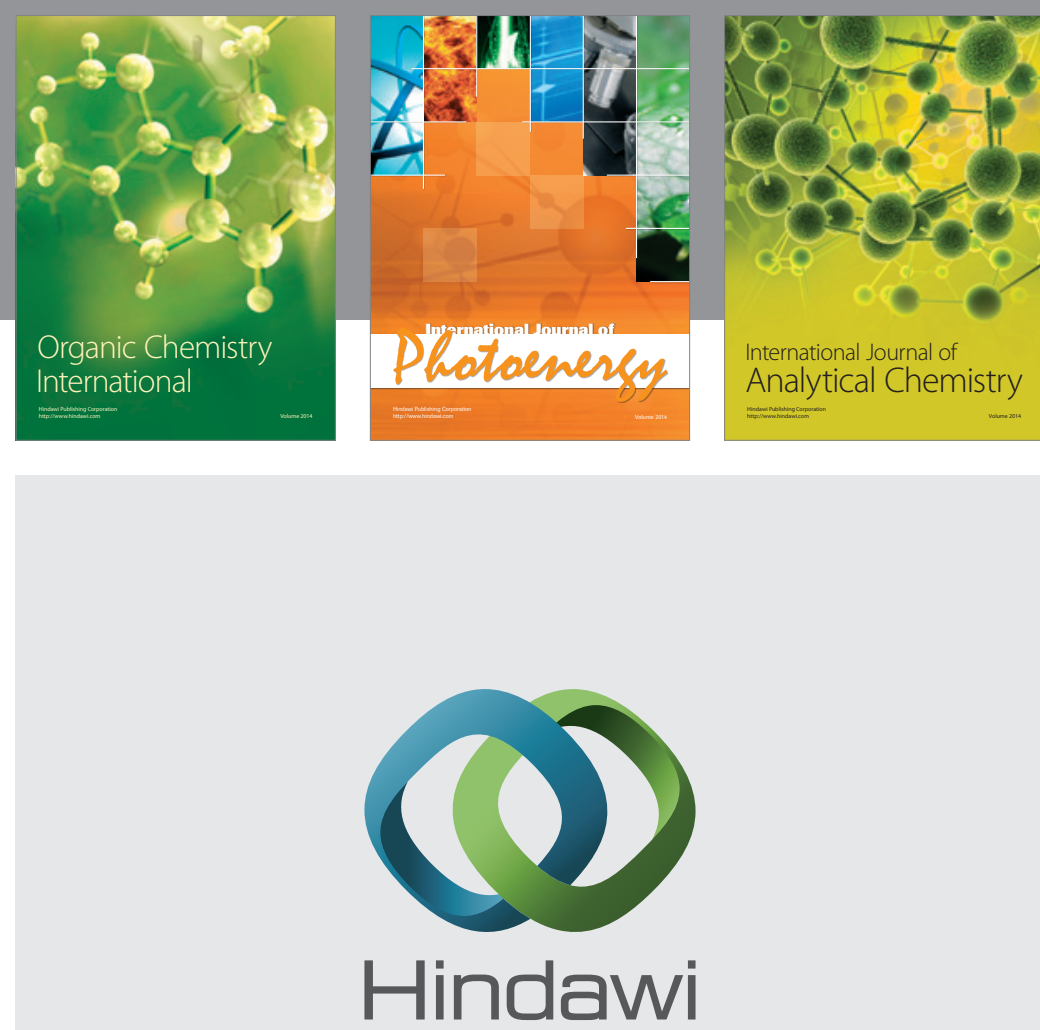

Submit your manuscripts at

http://www.hindawi.com
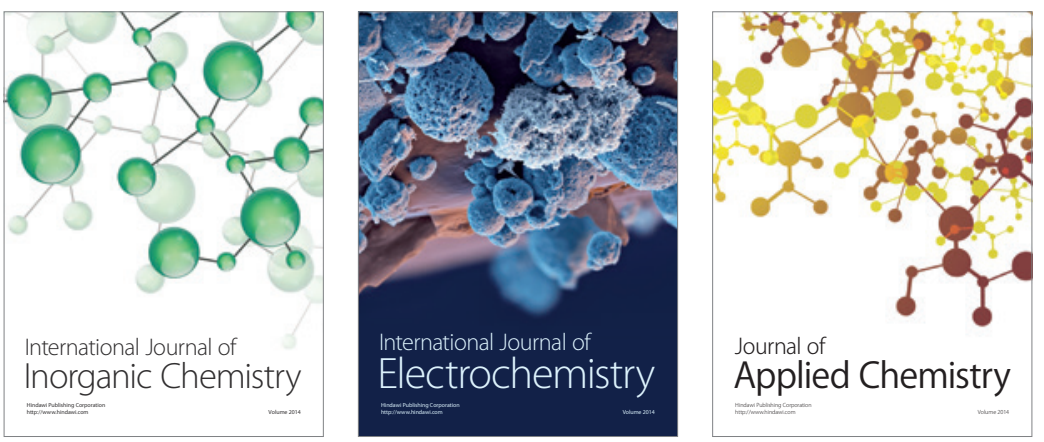

Journal of

Applied Chemistry
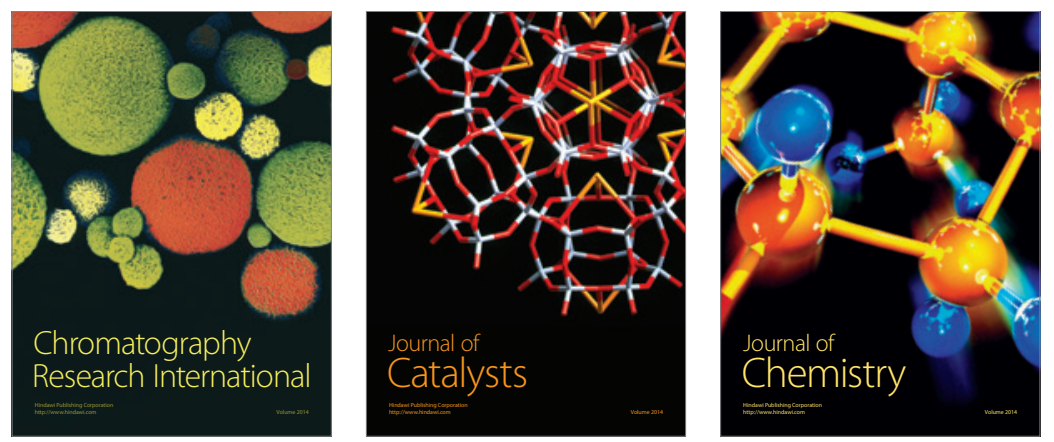
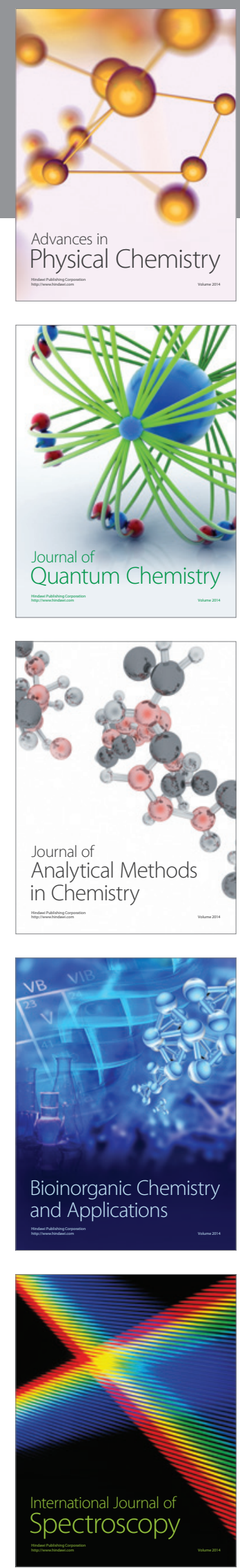